\title{
THE INFLUENCE OF SPECIFIED ADMIXTURES ON SOME CONCRETE BEHAVIORS
}

\author{
Hassan S. Abdul-Moghni \\ Associate Professor, Civil Engineering Dept., Faculty of Engineering, \\ Sana'a University, Sana'a, Yemen
}

(Received February 16, 2008 Accepted April 12, 2008)

\begin{abstract}
Superplasticizers are considered to be a new class of generic material. They have an efficient capability of increasing the workability without changing the mixture proportions, or reducing the required water content at equal slump.

The present study reports results of laboratory experimental works for the evaluation of the given admixture performance on some properties of a plain and a microsilica concrete. In addition, the study shows the effect of both superplasticizer and microsilica in producing a high strength concrete with moderate cement content.

The findings indicate that the addition of superplasticizers provides appreciable increase in concrete strength and durability. As well as the ability of production a high strength concrete due to the presence of the mentioned agents combination.
\end{abstract}

KEYWORDS: Superplasticizer, microsilica, compressive strength, splitting strength, concrete permeability.

\section{INTRODUCTION}

A superplasticizer with single specified mineral are widely used together as admixtures to produce high performance concrete, which provide a high strength and durability concrete. In order to achieve high strength and durability in concrete, it is necessary to have a low w/c ratio since both characteristics are basically controlled by this ratio. The most successful method to utilize superplasticizers thereby is the enabling a low w/c ratio to provide an accepted workability [1]. An intensive research work was performed by Ispas and Ionescu [2] who studied the influence of superplasticizers on some properties of concrete. They showed that, superplasticizers induced an increase in compressive strength by about $20-40 \%$ at 28 days compared to mixes without superplasticizers. A corresponding increase in the tensile strength was also gained as well. In addition, the static modulus of elasticity and the in-bond between reinforcement and concrete matrix were found to be higher. Similar findings were reported by Brooks et al [3] and Perechio et al [4].

The addition of microsilica to concrete was found to improve both strength and durability properties of hardened concrete by providing a more uniform distribution with a greater volume of hydration products and by decreasing the permeability of the cementitious matrix [5]. Recently an investigation was carried out by Rao [6] who studied the effect of microsilica on the performance of concrete. He reported that in all 
cases, the microsilica concrete has much higher resistance to liquid penetration, and similar results were reported by others $[7,8]$

\section{INVESTIGATION STRATEGIES}

It has been found from previous studies that, the common factor for reducing the strength and the other properties of concrete is the presence of connected voids and capillary pores. From this point, the capillary pores and voids should be decreased, and one of the best methods to do it is by controlling the w/c ratio of the mix [9]. During cement hydration process, some of these capillary pores will be closed due to the composition of the cementing gel. If the w/c ratio is greater than 0.4 in concrete, the amount of the produced gel would be insufficient to close all the capillary pores since these pores and voids can decrease the strength of the concrete. Therefore, the superplasticizer can be used to decrease the w/c ratio as much as possible while maintaining the same initial workability. Another admixture, which is known as microsilica, is used due to its acceptable fineness and high reactivity. Microsilica reacts with the calcium hydroxide which is produced during the hydration of cement, this leads to a replacement of a weak calcium hydroxide by a strong gel, and gives concrete of a high strength and very low permeability [8].

\section{TEST PROGRAMME}

The experimental work was carried out in the materials testing laboratory at the Faculty of Engineering, Sana'a University. The programme included testing of fresh and hardened concrete.

\section{MATERIALS}

The following materials were used throughout this work.

a) Cement Ordinary Portland Cement complying with ASTM C150-94.

b) Aggregate:

Natural sand from Saddah area as the fine aggregate. The grading conformed to ASTM C33-93. Crushed aggregates with a maximum size of $12.5 \mathrm{~mm}$ were used as the coarse aggregate. The grading conformed to ASTM C33-93. The specific gravities of the two aggregates were 2.64 and 2.81 for fine and coarse aggregate respectively. Both materials were used in their natural dry conditions.

c) High range water-reducing admixture

Superplasticizer of type (F), according to the ASTM C494, was used at $3 \%$ by weight of cement.

d) Microsilica admixture:

A highly active microsilica of $10 \%$ as partial replacement by weight of cement was used at a dosage of $3 \%$ of superplasticizer. 
With all of the three mixes, the w/c ratios were adjusted to maintain equal workability slump of $100 \pm 20 \mathrm{~mm}$. Mixes proportions were 1:1.6:3.2 by weight with a cement content of $350 \mathrm{~kg}$ per cubic meter of mix.

\section{CURING CONDITIONS}

After demoulding, the concrete specimens were stored in water for 7 days at laboratory temperature, and then the specimens were divided into two groups. The first group comprises specimens which were kept continuously saturated with water while the second one were left in oven at $105^{\circ} \mathrm{C}$ for 7 days, thereafter re-soaked in water, and that is to study the effect of drying on the specimens, and to ensure constant weight.

\section{PERMEABILITY MEASUREMENT}

Concrete permeability was measured using square slab specimens having a side length of $20 \mathrm{~cm}$ with a thickness of $12 \mathrm{~cm}$ as shown in Fig.1. Testing of specimens was performed at a curing time of 28 days according to the water penetration procedure stated in DIN 1048. Within this procedure a water pressure of $1 \mathrm{kp} / \mathrm{cm}^{2}$ was applied on the lower face of the specimens upward and kept constant for 48 hours, then increased to $3 \mathrm{kp} / \mathrm{cm}^{2}$ for 24 hours, and finally raised to $7 \mathrm{kp} / \mathrm{cm}^{2}$ for another 24 hours. Immediately after completion of the test, the test specimens were split in two halves and a maximum depth of water penetration was recorded. Three specimens were used at least, and the average value was considered.

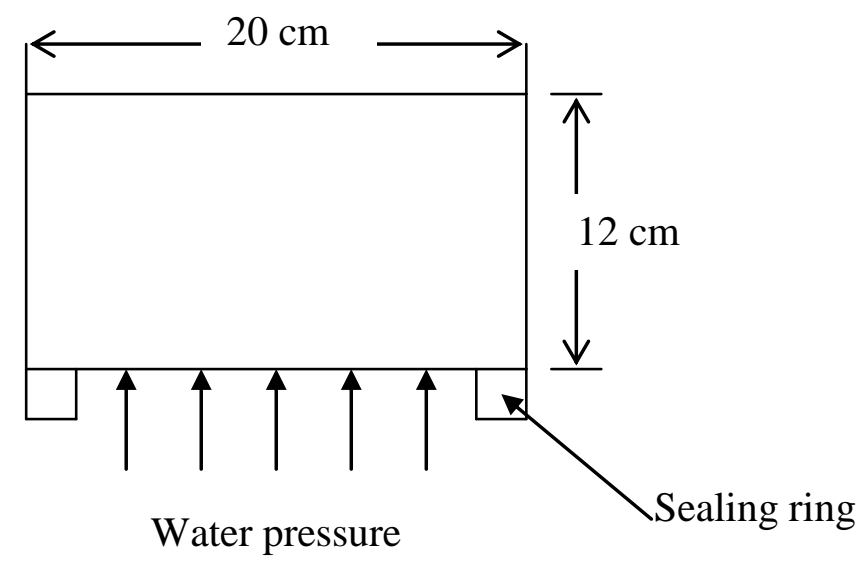

Fig. (1): Water impermeability testing on slabs $12 \mathrm{~cm} * 20 \mathrm{~cm} * 20 \mathrm{~cm}$.

\section{RESULTS AND DISCUSSION}

\section{Compressive_Strength}

Compressive strength test results of specimens with and without admixtures are given in table 1 and shown in figs. 2-7. These results may indicate the following aspects:

1. There is a considerable improvement in the strength of the admixtures concrete relative to the reference mix (without admixtures). After a total period of 90days 
the increase in compressive strength of the most cured specimens were 59.4 and $78.8 \%$ for superplasticizer and for combined addition of superplasticizer and microsilica concrete respectively compared to the reference concrete, tested at the same period. This increase in compressive strength with the presence of the admixtures was probably due to the reduction in the w/c ratio where the use of the superplasticizer could allow a reduction in the w/c by $25 \%$ whilst maintaining the initial workability while the combined addition of superplasticizer and microsilica could lead to a considerable reduction in w/c that is about $28 \%$ which allows the compressive strength to improve. The increase in strength may also be attributed to the better distribution of hydration products within the paste achieved by the addition of the admixtures. Furthermore, combined addition of superplasticizer with microsilica admixtures could present a new approach in producing high strength concrete with moderate content of cement. For example, concrete specimens having cement and microsilica contents of 315 and $35 \mathrm{Kg} / \mathrm{m}^{3}$ respectively cured for 90 days, resulted with a compressive strength of $77.3 \mathrm{MPa}$. This improvement in strength of the microsilica concrete specimens may be due to the pozzolanic and filler effects as well as the improvement in the bond strength of transition zone between the aggregate and cement paste [10] due to the fact that the microsilica is a very fine material, this reacts with the calcium hydroxide which, liberated during hydration of Portland cement forming a stable cementitious products. As a result, formation of very small pores and an improved aggregate-paste interface are taken place in concrete with microsilica, leading to reduced permeability and higher concrete strength.

2. The compressive strength of the 7 days moist cured specimens were increased by about $46.2 \%$ for reference concrete and between $25-28 \%$ for admixtures concrete after being oven dried at $105^{\circ} \mathrm{C}$ for 7 days as shown in fig. 3 . On the other hand, the compressive strength of the 7days oven dried specimens after 7 days curing was about $17.6 \%$ for reference concrete and between $5-14.3 \%$ for admixtures concrete more than that of the same concrete specimens which were continuously cured in water and tested at the same time. The increase in the compressive strength of the dried specimens may be referred to the removal of the free water from the structure of the paste, while lowering the strength of saturated concrete is probably due to the existence of the disjoining pressure within the cement paste. In addition, the increase rate of hydration, and the speed up of the hydration chemical reactions could be another reason which might led to the increased strength of concrete [11]. Similar findings were reported by Pihajavaara [12] who reported that the dry strengths were about two thirds higher than wet strengths.

3. The compressive strength of the reference concrete water soaked specimens reduced by $8.85 \%$ with respect to oven-dry one while the superplasticizer concrete reduced by $2.2 \%$ for the first 14 days of re-soaking in water since the microsilica concrete results showed an increase in compressive strength for the same period. Lowering the strength in reference mix is due to a higher w/c ratio and a greater porosity, leading to larger amount of absorbed water. Reduction was shown to a lower value for mixes of higher strength. Thereafter, the compressive strength of water soaked specimens began to increase continuously 
with age. At the age of 90 days, the oven dried concrete specimens showed a compressive strength less than that of the continuously moist cured concrete. This difference might be attributed to the induced cracks due to oven drying shrinkage, which could not be healed again when re-soaking the concrete specimens in water as a result of further hydration

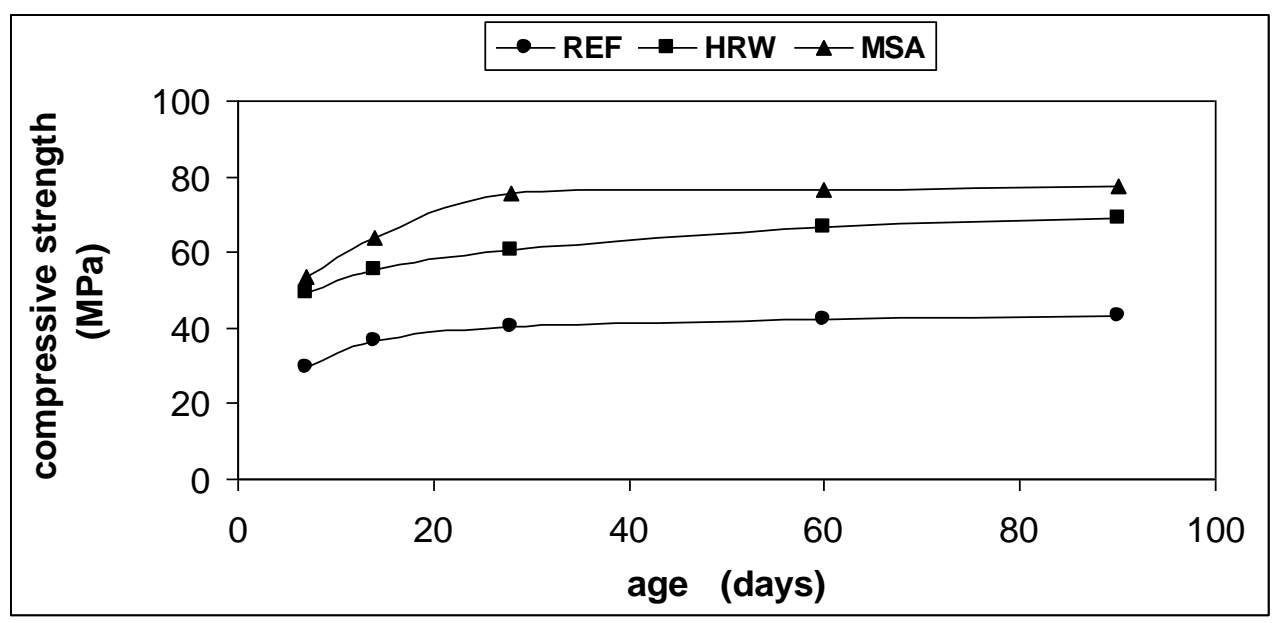

Fig - (2): Effect of the admixtures on the compressive strength.

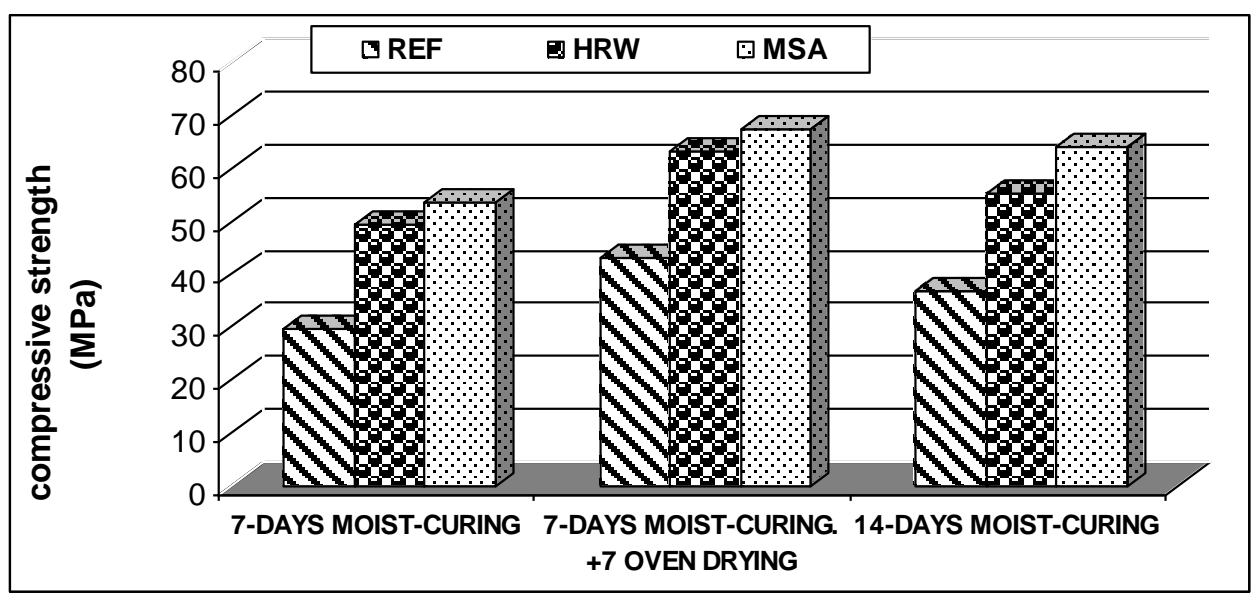

Fig - (3): Effect of oven drying on the compressive strength. 


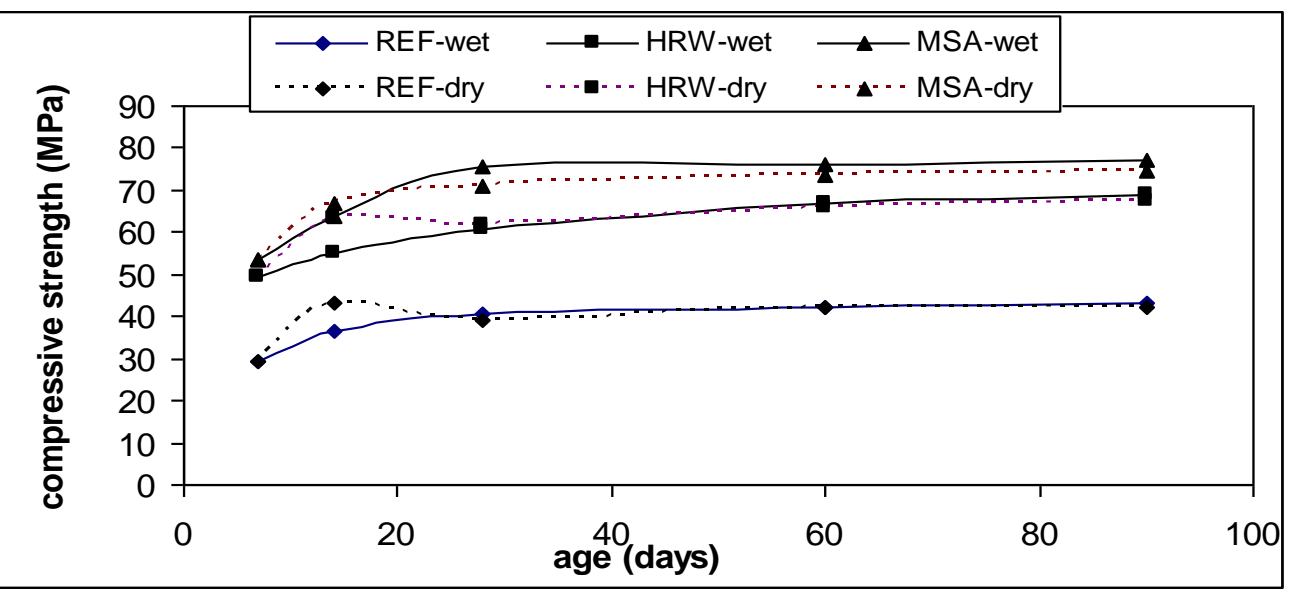

Fig . (4): Effect of the moist state on the compressive strength of the different mixes.

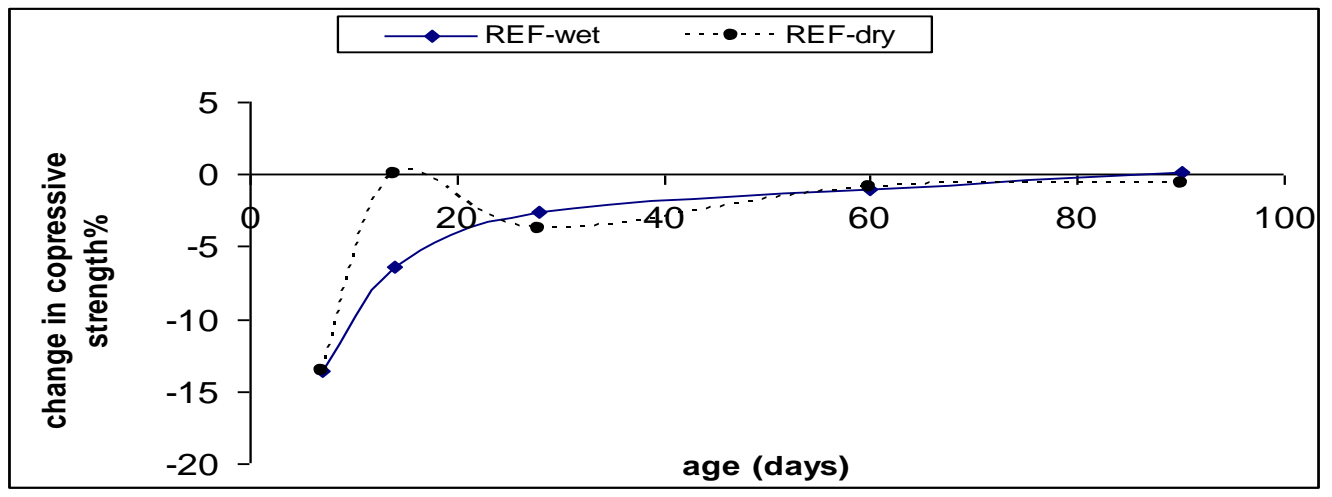

Fig . (5): Compressive strength as percent of oven drying strength for reference mix.

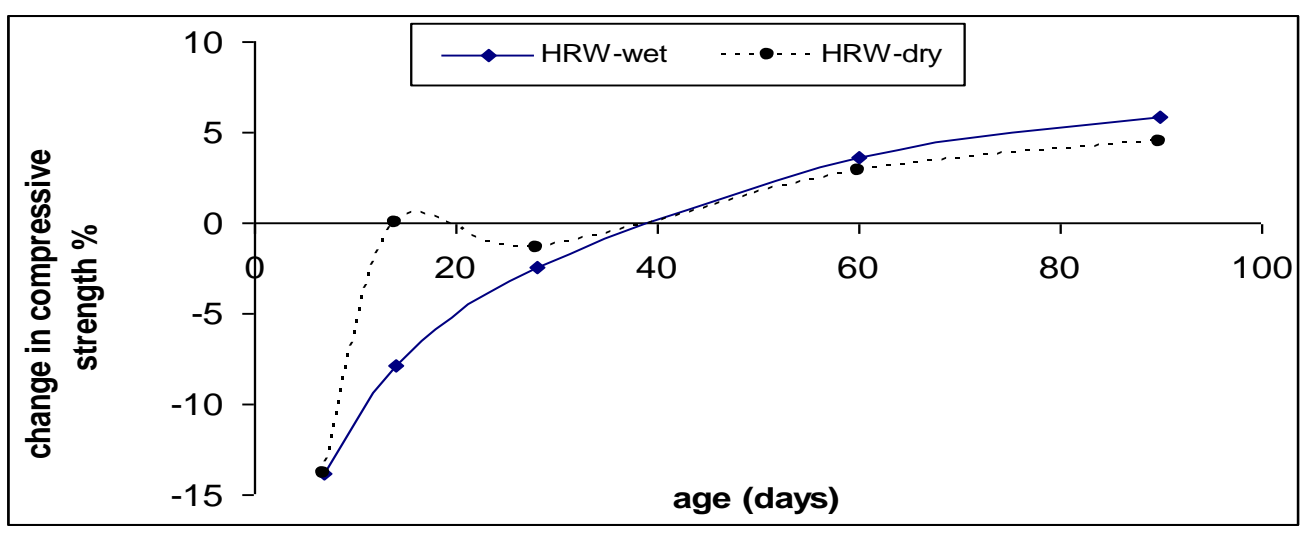

Fig . (6): Compressive strength as percent of oven drying strength for superplasticizer mix. 


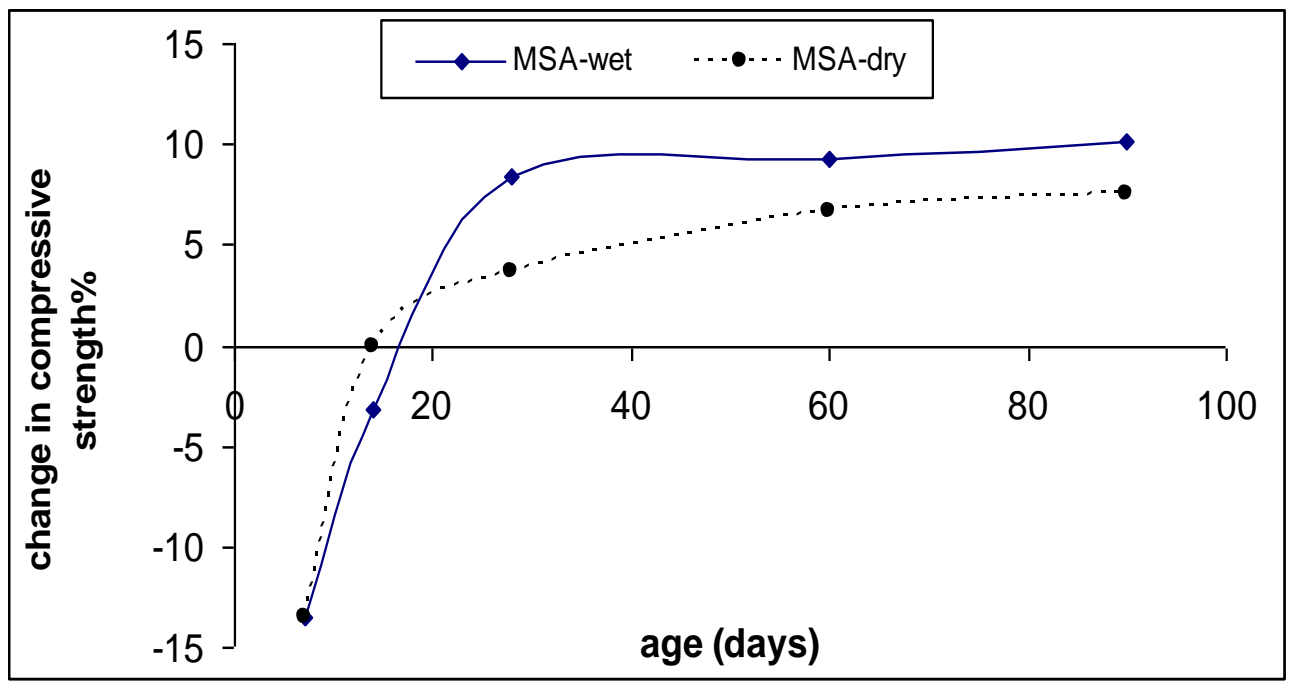

Fig . (7): Compressive strength as percent of oven drying strength for microsilica mix.

\section{SPLITTING TENSILE STRENGTH}

The splitting tensile results of concrete casted with and without admixtures are given in table 2 and illustrated in figs.8-10. According to the results, the following observations are made:

1. The admixtures concrete exhibits a higher splitting tensile strength than the corresponding reference concrete. At 90 days of moist curing the increase in the splitting tensile strength was about 37.1 and $46.1 \%$ of superplasticizer concrete and the combined addition of superplasticizer with microsilica admixture concrete respectively compared to the reference concrete tested at the same curing period. These results are confirmed by other investigations $[13,14]$ where the higher splitting tensile strength of the admixtures concrete may be attributed to the reduction in the w/c ratio leading to the lower amount and size of capillary pores that are present in the admixtures concrete compared with reference concrete. Furthermore the improvement in the splitting tensile strength of the microsilica concrete specimens may be referred to the performance of pozzlanic and filler. In general, the results indicated that, the pattern of the indirect tensile strength behavior is similar to the compressive strength.

2. The splitting tensile strength of the 7 days water cured specimens was increased by about $9-16.5 \%$ after being oven dried at $105^{\circ} \mathrm{C}$ for 7 days.

3. The splitting tensile strength of the 7 days oven dried specimens after being moist cured for 7days was between $0.7-7 \%$ more than that of similar concrete specimens continuously cured in water and tested at the same curing time.

4. The tensile splitting strength of the oven dry concrete specimens was reduced by about $7 \%$ for reference concrete and $1-2.4 \%$ for the admixtures concrete after 14 days of re-soaking in water. This reduction was then followed by an initial higher rate of strength gain, which gradually decreased with time, but the 
strength didn't reach that of the continuously moist cured concrete as show in fig. 10. After the age of 90 days the splitting strength increased by about $2.8 \%$ for the reference concrete and 4.3-9\% for the admixtures concrete compared with the dry strength before re-soaking in water.

5. The concrete specimens, which were continuously cured in water after demoulding without drying, showed a continuous increase in the tensile splitting strength. After the age of 90 days the increase in the strength was about 9.2-21\% higher than that of specimens cured for 14 days of wet curing, and was between 5.8-13.4\% higher than the oven dried concrete specimens and re-soaking with water to the same period of curing. The increase in the strength for the reference concrete specimens was the highest among all concrete mixes.

\section{PERMEABILITY OF CONCRETE}

The permeability of concrete consider to be a guide of its durability, and it is one of the prime necessities specified by the design codes and specifications of concrete structures, and for liquid retaining structures [15]. keeping the liquids in a storage is important with the need of concrete deterioration prevention due to percolation of aggressive agents. Water penetration results of concrete with and without admixtures are shown in fig. 11. The results revel that, the superplasticizer concrete has a lower permeability than the corresponding reference concrete specimens of similar workability, and this improvement in permeability may be attributed to the ability of the superplasticizer to reduce the mixing water. Most of the previous researches $[16,17]$ agree in that, the w/c ratio has a significant effect upon permeability, since reducing the $w / c$, leads to a reduction in the permeability too. Furthermore, the higher reduction in the permeability occurs in the admixtures concrete specimens of the combined addition of superplasticizer and microsilica. Obtaining a lower permeability of microsilica admixture concrete compared with others mixes can be attributed to the increase in density of concrete with microsilica admixture, resulting in the transformation of large pores into fine pores thereby causing pore refinement. Pore refinement occurs due to the conversation of $\mathrm{Ca}(\mathrm{OH})_{2}$ into a secondary hydration forming calcium silicate hydrate gel, which effectively fills up large voids in hydrated pozzolanic Portland cement concrete [18].

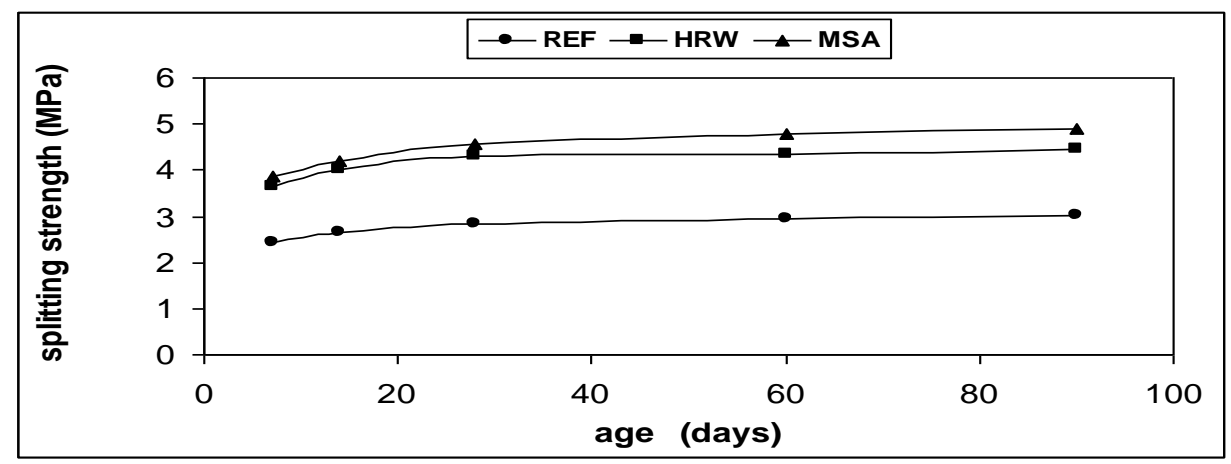

Fig - (8): Effect of the admixtures on the splitting tensile strength 


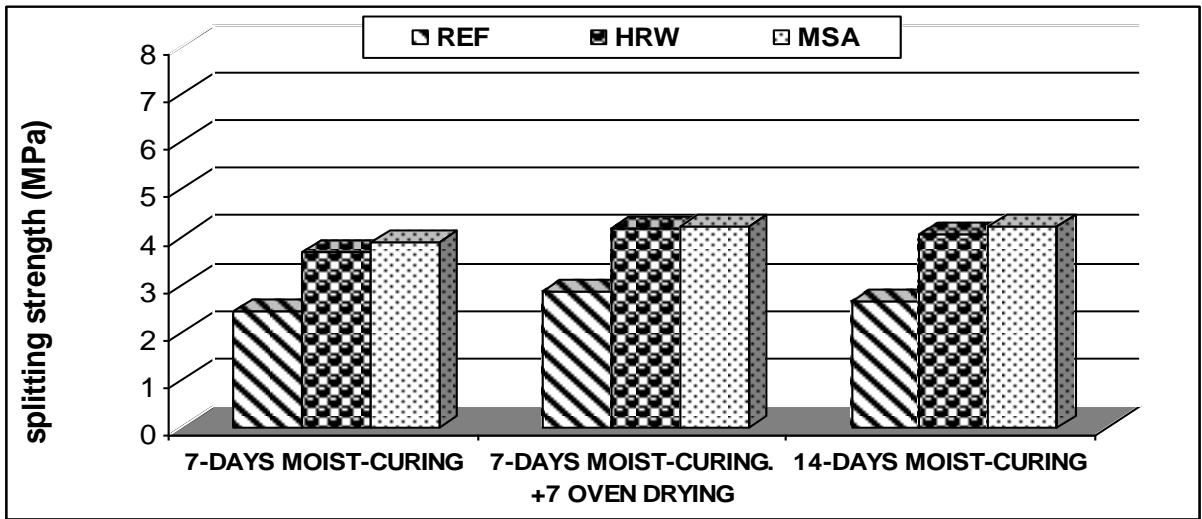

Fig . (9): Effect of oven drying on the splitting tensile strength.

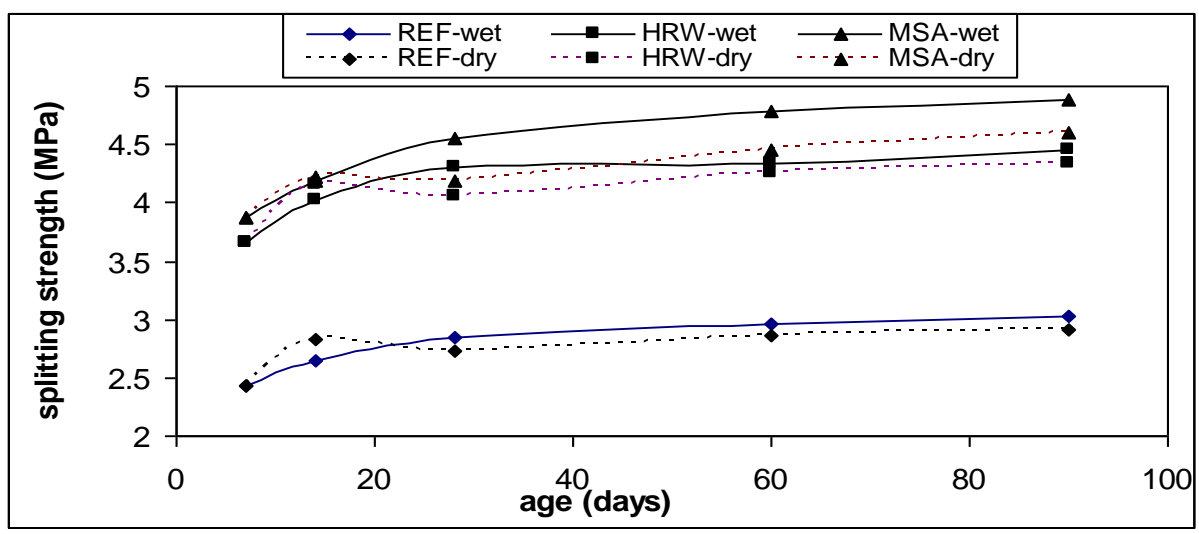

Fig . (10): Effect of the moist state on the splitting tensile strength of the different mixes.

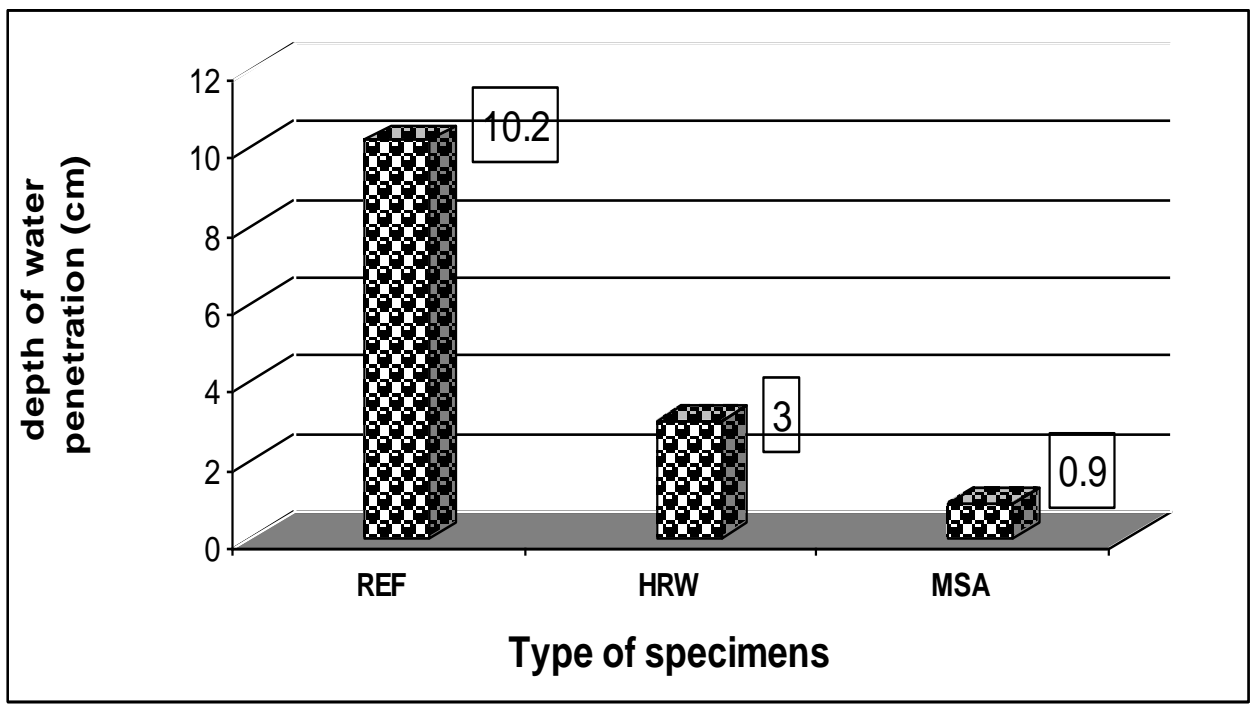

Fig . (11): Effect of admixtures on the depth of water penetration of concrete impermeability test after curing in water for 28 days. 


\begin{tabular}{|c|c|c|c|c|c|c|c|}
\hline \multirow{2}{*}{ हे } & \multirow[b]{2}{*}{ w/c } & \multirow{2}{*}{$\begin{array}{l}\text { Specimens } \\
\text { condition at } \\
\text { the second } \\
\text { week }\end{array}$} & \multicolumn{5}{|c|}{$\begin{array}{c}\text { Compressive strength (MPa) at different } \\
\text { curing time(days) }\end{array}$} \\
\hline & & & $\begin{array}{l}\text { 7days } \\
\text { wet } \\
\text { curing }\end{array}$ & 14 & 28 & 60 & 90 \\
\hline \multirow{2}{*}{ REF } & \multirow{2}{*}{0.54} & Wet & \multirow{2}{*}{29.43} & 36.6 & 40.41 & 42.04 & 43.23 \\
\hline & & Oven dried & & 43.03 & 39.24 & 42.08 & 42.37 \\
\hline \multirow{2}{*}{ HRW } & \multirow{2}{*}{0.40} & & \multirow{2}{*}{49.22} & 55.18 & 60.61 & 66.72 & 68.90 \\
\hline & & Oven dried & & 63.08 & 61.70 & 65.91 & 67.58 \\
\hline \multirow{2}{*}{ MSA } & \multirow{2}{*}{0.39} & Wet & \multirow{2}{*}{53.59} & 63.90 & 75.46 & 76.34 & 77.30 \\
\hline & & Oven dried & & 67.10 & 70.76 & 73.74 & 74.68 \\
\hline
\end{tabular}

Table 2: Test Results for the Splitting Tensile Strength of Concrete Specimens.

\begin{tabular}{|c|c|c|c|c|c|c|c|}
\hline \multirow{2}{*}{ 㝘 } & \multirow{2}{*}{$\mathbf{w} / \mathbf{c}$} & \multirow{2}{*}{$\begin{array}{l}\text { Specimens condition } \\
\text { at the second week }\end{array}$} & \multicolumn{5}{|c|}{$\begin{array}{c}\text { Splitting tensile strength (MPa) at different } \\
\text { curing time (days) }\end{array}$} \\
\hline & & & $\begin{array}{l}\text { 7days wet } \\
\text { curing }\end{array}$ & 14 & 28 & 60 & 90 \\
\hline \multirow{2}{*}{ REF } & \multirow{2}{*}{0.54} & Wet & \multirow{2}{*}{2.43} & 2.65 & 2.85 & 2.96 & 3.21 \\
\hline & & Oven dried & & 2.83 & 2.63 & 2.7 & 2.91 \\
\hline \multirow{2}{*}{ HRW } & \multirow{2}{*}{0.40} & Wet & \multirow{2}{*}{3.66} & 4.03 & 4.30 & 4.34 & 4.4 \\
\hline & & Oven dried & & 4.16 & 4.06 & 4.25 & 4.34 \\
\hline \multirow{2}{*}{ MSA } & \multirow{2}{*}{0.39} & Wet & \multirow{2}{*}{3.87} & 4.19 & 4.55 & 4.68 & 4.69 \\
\hline & & Oven dried & & 4.22 & 4.18 & 4.35 & 4.60 \\
\hline
\end{tabular}

REF : reference mix without admixtures

HRW : superplasticizer mix ( $3 \% \mathrm{HRW}$ )

MSA : combined addition of superplasticizer and microsilica mix ( $3 \% \mathrm{HRW}+10 \% \mathrm{MS})$ 


\section{CONCLUSIONS}

Considering the study results, the following conclusions may be drawn:

1. The compressive strength of the admixtured concrete is higher than that of nonadmixtured concrete, and the performance of the microsilica concrete is the best among of those admixtured. The combined addition of the superplasticizer and microsilica introduces a further approach of producing high strength concrete with moderate cement.

2. The concrete-containing admixtures exhibit higher tensile splitting strength than the corresponding reference concrete.

3. A significant reduction in the permeability was observed for the admixtured concretes.

4. A higher reduction in permeability was also detected in concrete specimens with the both superplasticizer and microsilica admixtures.

\section{REFERENCES}

1. Shirkavand, M., and Baggott, R., "Effects of Superplasticizer on Workability and Flexural Strength of Autoclaved Calcium Silicates" Cement and Concrete Research, Vol.25, No.7, 1995, pp.1512-1522.

2. Ispas, T., and Ionescu, I., "Aspects of Cementand Energy Economy in Precasting Plants by the Use of Superplasticizers", ACI Sp-68, 1986 pp. 319335.

3. Brooks, J.J., Wainwright, P.J., and Neville, A.M.M, "Time-Dependent Behavior of High-Early-Strength Concrete Containing a Superplasticizer" ACI Sp-68, 1986 pp. 81-99.

4. Perenchio, W.F., Whiting, D.A., and Kantro, D.L., "Water Reduction, Slump Loss, and Entrained Air-Void Systems as Influenced by Superplasticizers", ACI Sp-62, 1979, pp. 137-156.

5. Mangialardi, T., and Paolini, A.E., "Workability of Superplasticized Microsilica-Portland Cement Concretes', Cement and Concrete Research, Vol.18, No.3, 1988, pp. 351-362.

6. G. Appa Rao "Investigations on the performance of silica fume-incorporated cement pastes and mortars "Cement and Concrete Research, Volume 33, Issue 11, November 2003, Pages 1765-1770

7. R.M. de Gutiérrez, L.N. Díaz and S. Delvasto "Effect of pozzolans on the performance of fiber-reinforced mortars" Cement and Concrete Composites, Volume 27, Issue 5, May 2005, Pages 593-598.

8. Rosenberg, A.M., and Gaidis, J.M., "A New Mineral Admixture for HighStrength Concrete", Concrete International, Vol. April 1989, pp. 31-36.

9. Al-Khalaf, M.N. and Yousif, H.A. "Concrete Technology", University of Technology, Baghdad, 1984.

10. Vivekanandam, K., and Patnaikuni, I., "Transition Zone in High Performance concrete During Hydration", Cement and Concrete Research, Vol.27, No.6, 1997, pp. 817-823.

11. Mehta, P.K., "Concrete: Structure, Properties, and Materials", Prentice-Hall, New Jersey, 1986. 
12. Pihlajavaara, S.E. "Effect of Moisture Conditions on Strength, Shrinkage and Creep of Mature Concrete". Concrete and Cement Research, Vol. 4, No. 5, 1974, pp. 761-771.

13. S. Bhanja and B. Sengupta" Influence of silica fume on the tensile strength of concrete" Cement and Concrete Research, Volume 35, Issue 4, April 2005, Pages 743-747

14. Charif, H.J., and Alou, F., "Reduction of Deformations with the use of Concrete Admixtures: Admixtures for Concrete:" Chapman and Hall, London, 1990, PP.402-428

15. British Standards Institute, "The Structural Use of Concrete for Retaining Aqueous Liquids", B.S. 8007: 1987.

16. Manmohan, D., and Mehta, P.K., "Influence of Pozzolanic, Slag, and Chemical Admixtures on Pore Size Distribution and Permeability of Hardened Cement Pastes", Cement, Concrete, and Aggregate, Vol.3, No.1, 1981, pp. 63-67.

17. Saricimen, H., Maslehuddin, M., Al-Tayyib, A. and Al-Mana, A. "Permeability and Durability of Plain and Blended Cement Concretes Cured in Field and Laboratory Conditions", ACI Material Journal, Vol.92, No.2, March-April 1995, pp.111-116.

18. Hassan S. Abdul-Moghni, "The Permeability of Admixtured Concrete to Oil Products", II. International Symposium on Cement \&Concrete Technology in the 2000s, September 2000, Istanbul- Turkey, pp.312-321.

\section{دراسة تأثير مضافات محددة على بعض خواص الخرسانة}

تعتبر الملدنات المتفوقة صنف حديث من الإضافات الخرسانية التي لها القدرة على زيادة قابلية التشغيل

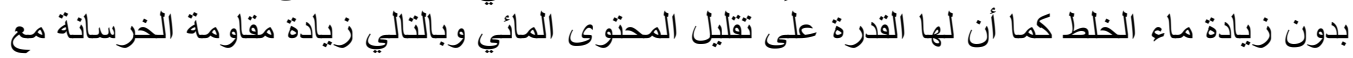
المحافظة على نفس قابلية التشغيل.

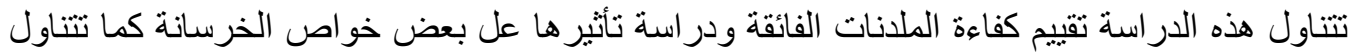

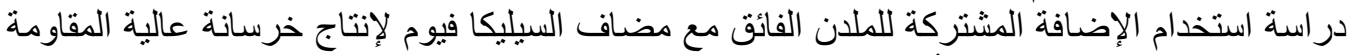

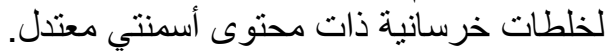

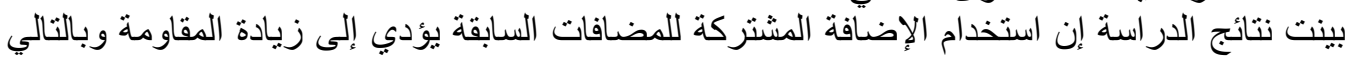
إنتاج خرسانة ذات مقاومة ومتانة عاليتين . 